\title{
Palladium Complexes Comprising C(4)-bound Diimidazolylidene Carbenes
}

\author{
Marion Heckenroth§ and Martin Albrecht* \\ §SCS Poster Prize Winner
}

\begin{abstract}
Imidazolium-derived palladium dicarbene complexes have been synthesized which feature either normal $\mathrm{C}(2)$ carbene bonding or abnormal $\mathrm{C}(4)$ bonding. Comparison of the reactivity of these complexes, in particular towards Lewis acids $\left(\mathrm{H}^{+}, \mathrm{Ag}^{+}\right)$, indicate consistently that $\mathrm{C}(4)$-bound carbenes are stronger donors than their $\mathrm{C}(2)$-bound analogs. As a consequence of this electronic impact, palladium complexes comprising $\mathrm{C}(4)$-bound dicarbene ligands were found to be efficient catalysts for olefin hydrogenation under mild conditions.
\end{abstract}

Keywords: Abnormal bonding $\cdot$ Catalytic alkene hydrogenation $\cdot \mathrm{N}$-Heterocyclic carbenes $\cdot$ Palladium

\section{Introduction}

In the last few years, N-heterocyclic carbenes (NHCs) have emerged as versatile ligands in transition-metal chemistry. They are strong neutral donors and thus powerful ligands for catalysis, and have been successfully applied in $\mathrm{C}-\mathrm{C}$ coupling reactions, ${ }^{[1]}$ olefin methathesis, ${ }^{[2]}$ hydroformylation, ${ }^{[3]}$ polymerization reactions, ${ }^{[4]}$ and $\mathrm{C}-\mathrm{H}$ bond activation. ${ }^{[5]}$ NHC ligands usually coordinate to the metal center at their $\mathrm{C}(2)$ position. Recently, abnormal C(4)-bonding (Scheme 1) has been discovered as a new NHC coordination mode. Such C(4)-bound carbenes represent a new type of ligand for transition metals. The reduced heteroatom stabilization may induce stronger donor properties, which will be advantageous for various catalytic applications.
${ }^{*}$ Correspondence: Prof. Dr. M. Albrecht

University of Fribourg

Department of Chemistry

Chemin du musée 9

$\mathrm{CH}-1700$ Fribourg

Tel.: + 41263008786

Fax: + 41263009738

E-mail: martin.albrecht@unifr.ch
Originally C(4)-bound carbene complexes have been synthesized by metallation of 2-pyridylimidazolium salt $\mathbf{1}$ with $\left[\mathrm{IrH}_{5}\left(\mathrm{PPh}_{3}\right)_{2}\right]$, which gave the abnormal complex 2 with the metal bound to C(4) instead of the expected C(2)-bound complex 3 (Scheme 1). ${ }^{[6]}$ The nature of the counter anion appeared to have a decisive influence on the binding mode. ${ }^{[7]}$ Strongly coordinating anions such as $\mathrm{Br}^{-}$form hydrogen bonds with the more acidic $\mathrm{C}(2)$-bound proton, thus favoring a proton transfer mechanism and heterolytic $\mathrm{C}(2)-\mathrm{H}$ cleavage. In con- trast weakly coordinating anions such as $\mathrm{BF}_{4}{ }^{-}$facilitate $\mathrm{C}(4)-\mathrm{H}$ oxidative addition. A similar anion influence has been observed upon palladation of bis(mesityl)imidazolium salts. In the presence of $\mathrm{Cs}_{2} \mathrm{CO}_{3}$, only the normal $\mathrm{C}(2)$-bound complex $\mathbf{4}$ is formed, while in the absence of additives the mixed normal/abnormal complex $\mathbf{5}$ is obtained.

A less anion-sensitive synthesis of $\mathrm{C}(4)$-bound carbene complexes involves the protection of the $\mathrm{C}(2)$ position in the imidazolium precursor. Accordingly, the

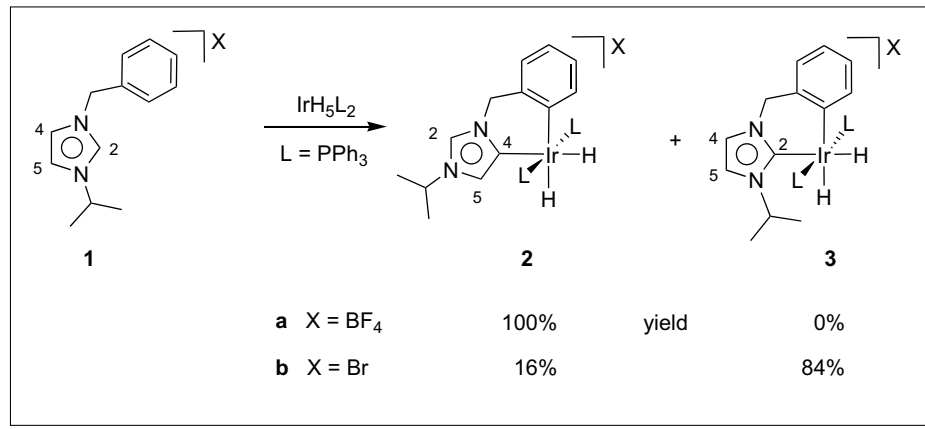

Scheme 1. Synthesis of $\mathrm{C}(4)$-bound carbene complexes with iridium polyhydrides

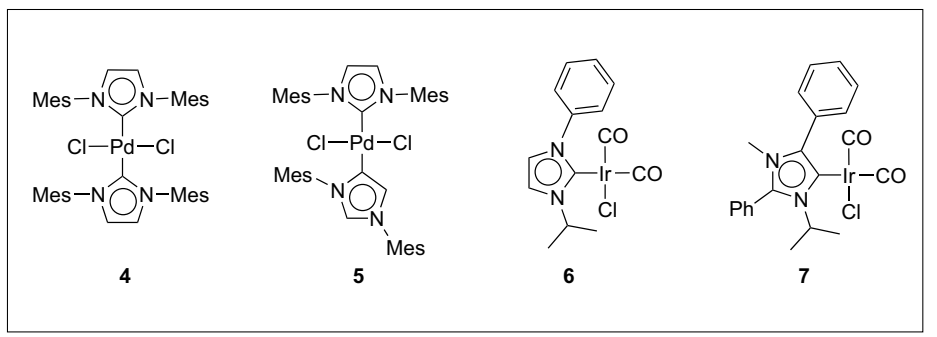

Fig. 1. Normal and abnormal NHC complexes of palladium(॥) and iridium(I) 


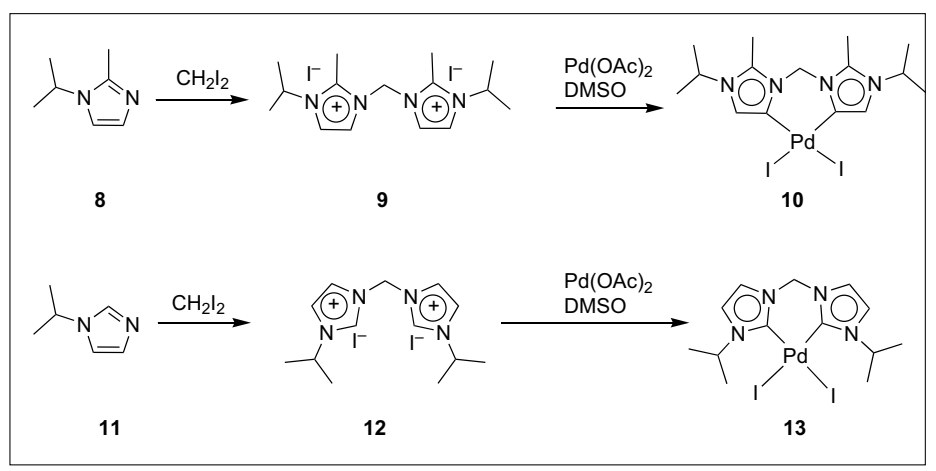

Scheme 2. Synthesis of C(2)- and C(4)-bound palladium complexes 10 and 13

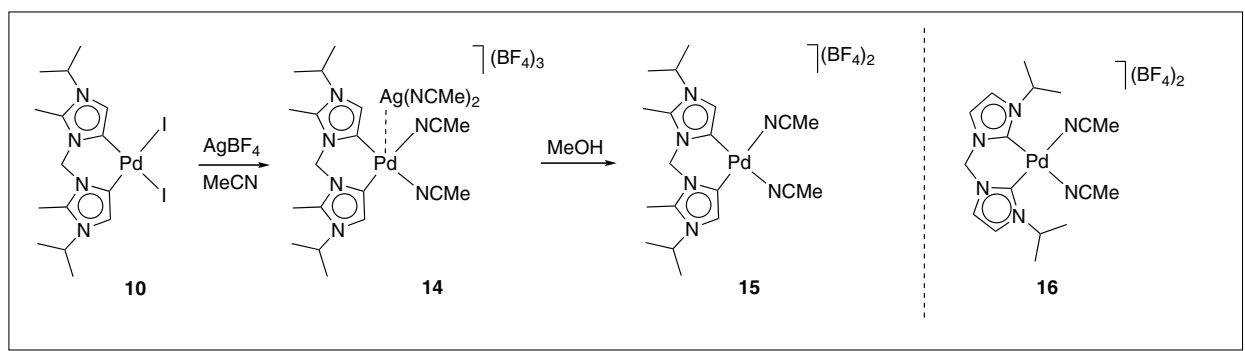

Scheme 3. Reactivity of 10 and 13 towards $\mathrm{AgBF}_{4}$

structurally very similar complexes $\mathbf{6}$ and 7 have been prepared in order to study the electronic impact of normal and abnormal carbenes (Fig. 1). ${ }^{[8]}$ Complex 7 shows much lower $v(\mathrm{CO})$ frequencies than complex $\mathbf{6}$, indicating that the abnormal carbene in 7 is a stronger donor than its normal $\mathrm{C}(2)$ bound analog in $\mathbf{6}$. In addition complex 4 and its $\mathrm{C}(4)$-bound analog $\mathbf{5}$ were tested in Suzuki and Heck reactions. ${ }^{[9]}$ The mixed C(2)-C(4) bound biscarbene complex 5 shows significantly better catalytic activity than 4. Apparently the bonding mode increases the catalytic performance of the metal center.

We are interested in further pursuing this approach, in particular to find systems that allow catalytic activation of less reactive bonds. In order to fully exploit the expected high trans effect of these abnormal carbenes, rigidly cis coordinating ligands are desirable. Our studies therefore focused on bidentate dicarbene ligands and their palladium complexes. Here we show that C(4)bound carbenes are stronger donors than their $\mathrm{C}(2)$-bound analogs. These properties have been successfully utilized to develop a new catalytic olefin hydrogenation process that operates under mild conditions.

\section{Synthesis of Complexes}

The use of $\mathrm{C}-\mathrm{H}$ bond activation as a rational synthetic route for C(4)-metallation of imidazolium salts requires the functionalization of the $\mathrm{C}(2)$ position to prevent normal $\mathrm{C}(2)$ binding. Therefore the imidazole 8 with a methyl substituent at $\mathrm{C}(2)$ was chosen as starting material. It was readily converted into the diimidazolium salt 9 by using diiodomethane (Scheme 2). Metallation was successfully accomplished with $\mathrm{Pd}(\mathrm{OAc})_{2}$ in DMSO, thus yielding the abnormal dicarbene complex 10 (Scheme 2). ${ }^{[10]}$ A similar route starting from 2-H-isopropylimidazol (11) gave the complex 13 with carbene ligands bound normally via $\mathrm{C}(2){ }^{[11]}$ Both complexes 10 and 13 were obtained in high yield and their structures were confirmed by spectroscopy and X-ray analysis.

\section{Reactivity Towards Lewis Acids}

In the presence of $\mathrm{H}_{2} \mathrm{SO}_{4}$, the $\mathrm{C}(4)$ bound complex $\mathbf{1 0}$ dissociates rapidly to give a diimidazolium salt similar to $\mathbf{9}$. In contrast the $\mathrm{C}(2)$-bound analog $\mathbf{1 3}$ is stable under identical conditions for days, even upon heating. Obviously the palladium center is less acid-stable in abnormal complexes. The metal-bound carbon is a possible site of direct proton attack, since this position is not shielded by wingtip groups as in 13. Alternatively proton-binding can occur initially at the palladium center, forming a Pd-hydrogen intermediate. Subsequent hydrogen migration to the metal-bound carbon with concomitant cleavage of the $\mathrm{Pd}-\mathrm{C}$ bond also gives the diimidazolium salt. We were unable to detect any $\mathrm{Pd}-\mathrm{H}$ intermediate by in situ ${ }^{1} \mathrm{H}$ NMR spectroscopy, but reactivity studies of complex $\mathbf{1 0}$ towards other Lewis acids supports such a metalmediated pathway.

The abnormal complex 10 reacts with $\mathrm{AgBF}_{4}$ to give the unexpected bimetallic

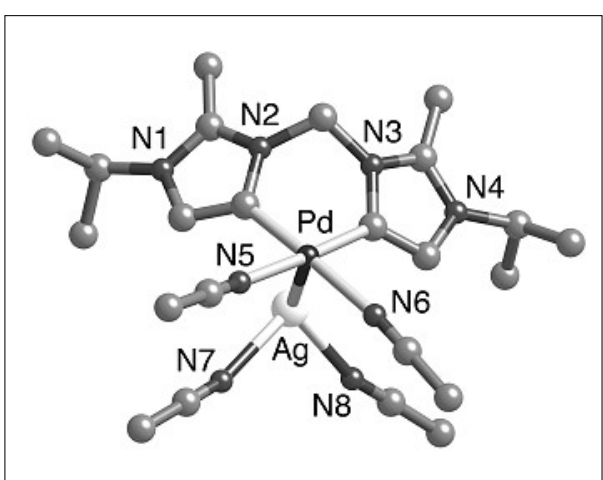

Fig. 2. Molecular structure of the bimetallic species 14 displaying a short palladium-silver interaction

complex 14 (Scheme 3). ${ }^{[10]}$ Atomic absorption spectroscopy indicates the presence of equimolar quantities of silver and palladium in complex 14. The structure was unequivocally confirmed by X-ray analysis and shows a remarkably short Pd...Ag contact of 2.8701(6) $\AA$ (Fig. 2). ${ }^{[12]}$ This supports a strong $\mathrm{Pd}-\mathrm{Ag}$ bond in complex 14 . Hence this complex may represent a model for the postulated Lewis acid-Lewis base intermediate in the reaction of $\mathbf{1 0}$ with $\mathrm{H}^{+}$ ions.

The silver-free bissolvento complex $\mathbf{1 5}$ is obtained by dissolving the silver adduct in $\mathrm{MeOH}$ or DMSO (Scheme 3). These solvents are nucleophilic enough to compete with the palladium center and hence promote the transfer of $\mathrm{Ag}^{+}$from palladium to a solvent oxygen site. In contrast to $\mathbf{1 0}$, the normal dicarbene complex $\mathbf{1 3}$ gave directly the expected bissolvento complex 16 upon addition of $\mathrm{AgBF}_{4}$ (Scheme 3). [11]

Apparently, the palladium center in the abnormal carbene complex $\mathbf{1 0}$ is electronrich enough to coordinate to a Lewis acid such as $\mathrm{Ag}^{+}$. This suggests that the palladium is more nucleophilic in $\mathrm{C}(4)$-bound carbene complexes than in $\mathrm{C}(2)$-bound analogs, which may be due to the stronger donor ability of abnormal carbenes. Additionally, steric effects may also contribute to the observed reactivity differences. In the $\mathrm{C}(2)$-bound complex $\mathbf{1 3}$ the $\mathrm{Pd}-\mathrm{C}$ bond is shielded by the $i s o$-propyl wingtip group, which may prevent coordination of Lewis acids to the metal center. Current investigations in our laboratories on complexes that feature identical steric environments indicate however that steric effects are negligible and that, indeed, the reactivity differences are due to the electronic effects. This hypothesis was further verified by $\mathrm{X}$-ray photoelectron spectroscopy (XPS). The $3 \mathrm{~d}$ electron bonding energies at the palladium center in $\mathbf{1 0}$ are $0.6 \mathrm{eV}$ lower than those in the $\mathrm{C}(2)$-bound complex 13. This difference implies a higher electron density at the metal center when bound to abnormal carbenes and supports the notion that 
C(4)-bound carbenes are stronger electron donors than their $\mathrm{C}(2)$-bound analogs.

\section{Catalysic Applications}

The impact of $\mathrm{C}(4)$-bound carbene ligands has been exploited in catalysis, particularly in Suzuki cross-coupling and in alkene hydrogenation. Complexes $\mathbf{1 0}$ and 13 both catalyze the Suzuki cross-coupling of aryl bromides with phenyl boronic acid (Scheme 4). For both complexes yields are acceptable but high catalyst loadings and long reaction times are required. Accordingly TONs and TOFs are very low.

The limited activity of complexes $\mathbf{1 0}$ and $\mathbf{1 3}$ in cross-coupling reactions may be rationalized by the fact that $\mathrm{Pd}^{0}$ formation is required for initiation of the catalytic cycle. Reduction of the metal in $\mathbf{1 0}$ or $\mathbf{1 3}$ seems unfavorable because of the strong donor ability of the dicarbene ligands and because of the rigid $85^{\circ}$ bite angle, which favors a square planar metal geometry.

Given the high electron density at palladium, oxidative addition reactions may be more likely to be mediated by complexes such as 10. Preliminary studies concentrated on the hydrogenation of cyclooctene and indicated appreciable activity for the solvento complex 15 (Scheme 5). Carbene C(4)-bonding seems to be essential for high catalytic activity, since the $\mathrm{C}(2)$-bound ana$\log \mathbf{1 6}$ is a significantly less active hydrogenation catalyst (Fig. 3).

Hydrogenation reactions were typically run under mild conditions, that is, at room temperature and under atmospheric $\mathrm{H}_{2}$ pressure. Conversions are fastest when using EtOH as solvent. Under these conditions hydrogenation of cyclooctene is complete in less than $5 \mathrm{~h}$, whereas in nonpolar solvents like toluene the conversion is incomplete even after prolonged reaction times. Strongly coordinating solvents such as DMF appear to poison the catalytic activity of the complex and no conversion is observed at all.

Under the applied conditions, $1 \mathrm{~mol} \%$ catalyst loading is required for useful conversions. At $0.1 \mathrm{~mol} \%$ loading, cyclooctene reduction proceeds to about $70 \%$ and at even lower loadings $(0.01 \mathrm{~mol} \%)$ only traces of product were detected. Since hydrogenation is supposed to be initiated by oxidative addition of $\mathrm{H}_{2}$ to the metal center, the high catalytic activity of $\mathbf{1 5}$ may be another consequence of the exceptional donor power of abnormally C(4)-bound carbenes.

\section{Conclusions}

Detailed analyses and reactivity studies have shown that $\mathrm{C}(4)$-bound carbenes are exceptionally strong donor ligands that sur-

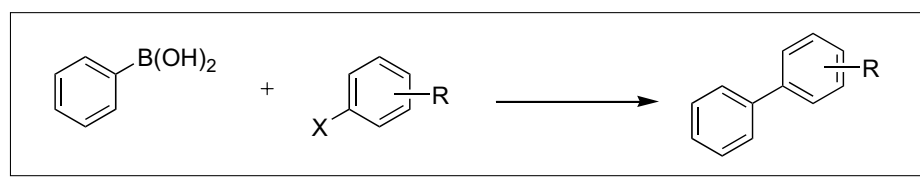

Scheme 4

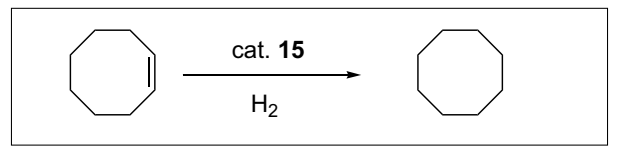

Scheme 5.

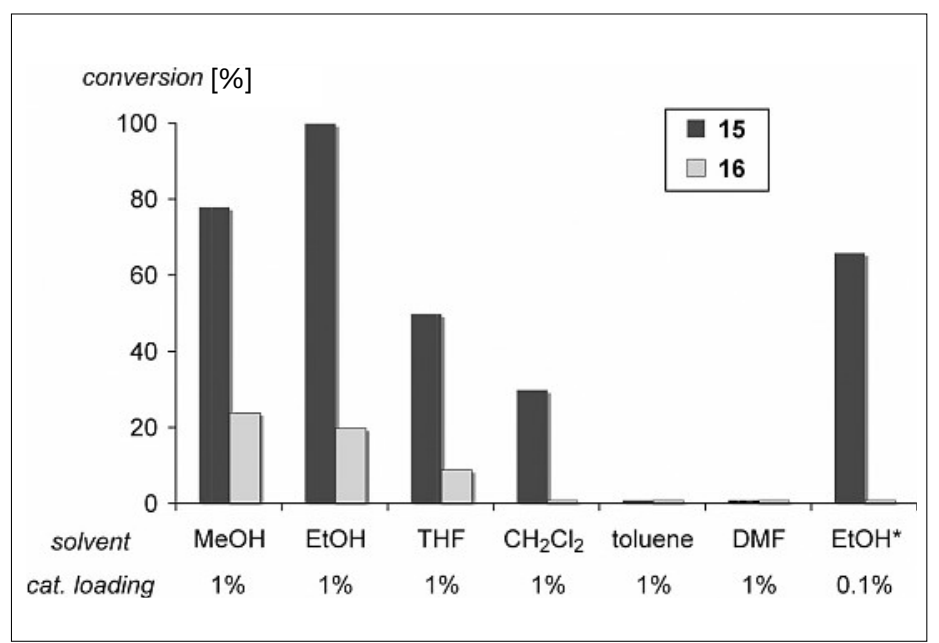

Fig. 3. Hydrogenation of cyclooctene with the $\mathrm{C}(4)$-bound dicarbene complex 15 and its normal analog 16 in different solvents. Conversions (GC) determined after $8 \mathrm{~h}$ ( ${ }^{*}$ after $24 \mathrm{~h}$ ).

pass $\mathrm{C}(2)$-bound carbenes. This electronic impact has remarkable consequences on the stability and reactivity of the coordinated metal center. We have exploited these effects in catalytic alkene hydrogenation and have developed an efficient system based on abnormal carbene bonding. Similar complexes may become promising candidates for the activation of other less reactive bonds.

\section{Acknowledgements}

We thank Dr. A. Neels (University of Neuchâtel) for X-ray analyses, Dr. G. M. Garnier and Prof. P. Aebi (University of Neuchâtel) for XPS measurements, and Ms. E. Kluser for experimental assistance. This work was financially supported by the Swiss National Science Foundation. M. A. is very grateful for an Alfred Werner Assistant Professorship.

Received: February 25, 2008

[1] a) 'N-Heterocyclic Carbenes in Synthesis', Ed. S. P. Nolan, Wiley-VCH, Weinheim, 2006; b) V. P. W. Böhm, T. Weskamp, C. W. K. Gstöttmayr, W. A. Herrmann, Angew. Chem., Int. Ed. 2000, 39, 1602.

[2] a) T. Weskamp, W.C. Schattenmann, M. Spiegler, W. A. Herrmann, Angew. Chem., Int. Ed. 1998, 37, 2490; b) T. Weskamp, F. J. Kohl, W. Hieringer, D. Gleich, W. A. Herrmann, Angew. Chem., Int. Ed. 1999, 38, 2416; c) M. Scholl, S. Ding, C. W. Lee, R. H. Grubbs, Org. Lett. 1999, 1, 953; d) M.S. Sanford, J.A. Love, R.H. Grubbs, J. Am. Chem. Soc. 2001, 123, 6543.

[3] a) W. A. Herrmann, J. A. Kulpe, W. Konkol, H. Bahrmann, J. Organomet. Chem. 1990, 389, 85; b) W. A. Herrmann,
C. W. Kohlpaintner, Angew. Chem. 1993, 105, 1588.

[4] a) M. G. Gardiner, W. A. Herrmann, C.-P. Reisinger, J. Schwarz, M. Spiegler, J. Organomet. Chem. 1999, 572, 239; b) J. Schwarz, E. Herdtweck, W. A. Herrmann, M. G. Gardiner, Organometallics 2000, 19, 3154.

[5] a) M. Muehlhofer, T. Strassner, W. A. Herrmann, Angew. Chem., Int. Ed. 2002, 41, 1745; b) T. Strassner, M. Muehlhofer, A. Zeller, E. Herdtweck, W. A. Herrmann, J. Organomet. Chem. 2004, 689, 1418.

[6] S. Gründemann, A. Kovasevic, M. Albrecht, J. W. Faller, R. H. Crabtree, Chem. Commun. 2001, 2274.

[7] L. N. Appelhans, D. Zuccaccia, A. Kovacevic, A. R. Chianese, J. R. Miecznikowski, A. Macchioni, E. Clot, O. Eisenstein, R. H. Crabtree, J. Am. Chem. Soc. 2005, 125, 16299.

[8] A. R. Chianese, A. Kovacevic, B. M. Zeglis, J. W. Faller, R. H. Crabtree, Organometallics 2004, 23, 2461.

[9] H. Lebel, M. K. Janes, A. B. Charette, S. P. Nolan, J. Am. Chem. Soc. 2004, 126, 5046.

[10] M. Heckenroth, E. Kluser, A. Neels, M. Albrecht, Angew. Chem., Int. Ed. 2007, 46, 6293.

[11] M. Heckenroth, A. Neels, H. StoeckliEvans, M. Albrecht, Inorg. Chim. Acta 2006, 359, 1929.

[12] a) Y. Liu, K. H. Lee, J. J. Vittal, T. S. A. Hor, J. Chem. Soc. Dalton Trans. 2002 , 2747; b) J. Forniés, A. Martin in 'Metal Clusters in Chemistry', Eds. P. Braunstein, L. A. Oro, P. R. Raithby, Vol. 1, Wiley$\mathrm{VCH}$, Weinheim, 1999, p 417. 